\title{
The Practice of Writing Curricula Vitae among the Lower Government Employees in the Late Ottoman Empire: Workers at the şeyhülislâm's Office
}

Jun Akiba

\section{OpenEdition}

\section{Journals}

Electronic version

URL: http://journals.openedition.org/ejts/1503

DOI: 10.4000/ejts.1503

ISSN: $1773-0546$

Publisher

EJTS

Electronic reference

Jun Akiba, «The Practice of Writing Curricula Vitae among the Lower Government Employees in the Late Ottoman Empire: Workers at the Seyhülislâm's Office », European Journal of Turkish Studies [Online], 6 | 2007, Online since 31 December 2007, connection on 16 February 2020. URL : http:// journals.openedition.org/ejts/1503; DOI : 10.4000/ejts.1503 
Citation : Akiba, Jun (2007) 'The Practice of Writing Curricula Vitae among the Lower Government Employees in the Late Ottoman Empire: Workers at the Şeyhülislâm's Office,' European Journal of Turkish Studies, Thematic Issue Nº, IIIliterate Knowledge, URL : http://www.ejts.org/document1503.html

To quote a passage, use paragraph (§).

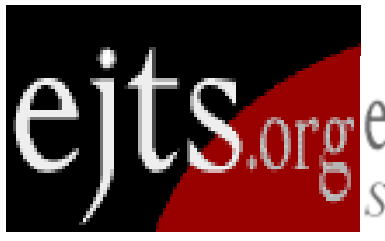

european journal of turkish studies

Social Sciences on Contemporary Turkey

\section{Tables}

\begin{tabular}{|c|c|c|c|c|c|c|c|c|}
\hline \multicolumn{9}{|c|}{ Pütürgeli Workers in the Personnel Record Dossiers } \\
\hline & \multirow[t]{2}{*}{ Name } & \multirow{2}{*}{$\begin{array}{l}\text { Original } \\
\text { No. }\end{array}$} & \multirow{2}{*}{$\begin{array}{l}\text { Year } \\
\text { of } \\
\text { birth }\end{array}$} & \multirow{2}{*}{$\begin{array}{l}\text { Position at the time of pre- } \\
\text { paring CV }\end{array}$} & \multicolumn{3}{|c|}{ Language } & \multirow[t]{2}{*}{ Education } \\
\hline & & & & & $T$ & $\mathrm{~K}$ & Unsp. & \\
\hline 1 & Bekir Ağa & 309 & 1845 & Tahrirat Kalemi odacılığı & & & & private* $^{*}$ \\
\hline 2 & Yusuf Ağa & 294 & 1848 & Daire-i Meşihat hademeliği & $S$ & $S$ & & ibtidal* $^{*}$ \\
\hline 3 & $\begin{array}{l}\text { Mustafa } \\
\text { Ağa }\end{array}$ & 341 & 1853 & Meclis-i Intihab odacılığı & & & & $\begin{array}{l}\text { primary } \\
\text { education* }\end{array}$ \\
\hline 4 & $\begin{array}{l}\text { Mehmed } \\
\text { Ağa }\end{array}$ & 326 & 1856 & $\begin{array}{c}\text { Meclis-i Tedkikat-ı Şer'iye } \\
\text { odacılığı }\end{array}$ & $S$ & $S$ & & \\
\hline 5 & $\begin{array}{l}\text { İbrahim } \\
\text { Ağa }\end{array}$ & 327 & 1866 & Fetvahane odacılığı & & & $\Delta \mathrm{RW}$ & \\
\hline 6 & $\begin{array}{l}\text { Mehmed } \\
\text { Ağa }\end{array}$ & 344 & 1872 & $\begin{array}{c}\text { Meclis-i Tedkikat-ı Şer'iye } \\
\text { odacılığı }\end{array}$ & & & & sibyan $^{*}$ \\
\hline 7 & $\begin{array}{l}\text { Hüseyin } \\
\text { Ağa }\end{array}$ & 318 & 1877 & Ders Vekâleti odacılığı & & & & ibtidai \\
\hline 8 & $\begin{array}{l}\text { Mustafa } \\
\text { Ağa }\end{array}$ & 383 & 1880 & Sicil Kalemi odacılığı & & & & \\
\hline 9 & $\begin{array}{l}\text { Hasan } \\
\text { Efendi }\end{array}$ & 385 & 1884 & $\begin{array}{c}\text { Idare-i Emval-i Eytam } \\
\text { odacılığı }\end{array}$ & RW & $S$ & & $\begin{array}{l}\text { ibtidai } \\
\text { rüşdiye }\end{array}$ \\
\hline 10 & Ömer Ağa & 290 & 1889 & Meşihat odacılığı & RW & $S$ & & ibtidai \\
\hline 11 & $\begin{array}{l}\text { Osman } \\
\text { Efendi }\end{array}$ & 5277 & 1889 & Sicil odacılığı & SR & & & sibyan \\
\hline 12 & $\begin{array}{l}\text { Hüseyin } \\
\text { Ağa }\end{array}$ & 662 & 1892 & Ders Vekâleti odacılığı & $S$ & $S$ & $\Delta \mathrm{W}$ & village school* \\
\hline 13 & Hasan Ağa & 5399 & 1892 & Meşihat hademeliği & RW & & & ibtidai \\
\hline 14 & Osman Ağa & 374 & 1896 & Mahzen-i Sicil hammallığı & & & & ibtidai* $^{*}$ \\
\hline 15 & $\begin{array}{l}\text { Mehmed } \\
\text { Efendi }\end{array}$ & 5327 & 1900 & $\begin{array}{c}\text { Daire-i Meşihat evrak tevzi } \\
\text { memurluğu }\end{array}$ & RW & & & $\begin{array}{l}\text { primary } \\
\text { education } \\
\text { rüşdiye }\end{array}$ \\
\hline
\end{tabular}


Citation : Akiba, Jun (2007) 'The Practice of Writing Curricula Vitae among the Lower Government Employees in the Late Ottoman Empire: Workers at the Şeyhülislâm's Office,' European Journal of Turkish Studies, Thematic Issue Nº, IIIliterate Knowledge, URL : http://www.ejts.org/document1503.html

To quote a passage, use paragraph (§).

\begin{tabular}{|c|c|c|c|c|c|c|c|c|}
\hline \multicolumn{9}{|c|}{ Pütürgeli Workers in the Personnel Record Registers } \\
\hline & \multirow[t]{2}{*}{ Name } & \multirow{2}{*}{$\begin{array}{c}\text { Original } \\
\text { No. }\end{array}$} & \multirow{2}{*}{$\begin{array}{l}\text { Year } \\
\text { of } \\
\text { birth }\end{array}$} & \multirow{2}{*}{$\begin{array}{l}\text { First position after the reor- } \\
\text { ganization of } 1909\end{array}$} & \multicolumn{3}{|c|}{ Language } & \multirow[t]{2}{*}{ Education } \\
\hline & & & & & $\mathrm{T}$ & K & Unsp. & \\
\hline 16 & $\begin{array}{l}\text { Mehmed } \\
\text { Ağa }\end{array}$ & $7 / 3$ & 1864 & Meşihat Kapı Ağalığı & & & & private \\
\hline 17 & $\begin{array}{l}\text { Mehmed } \\
\text { Efendi }\end{array}$ & $7 / 58$ & 1874 & Daire-i Meşihat hademeliği & & & $\mathrm{RW}^{*}$ & ibtidai (Ist.) \\
\hline 18 & Halil Efendi & $7 / 143$ & 1884 & Daire-i Meşihat hademeliği & & & & $\begin{array}{l}\text { rüşdiye (Ist.) } \\
\text { medrese }\end{array}$ \\
\hline
\end{tabular}

\begin{tabular}{|c|c|c|c|c|c|c|c|c|}
\hline \multicolumn{9}{|c|}{ Selected Examples from Non-Pütürgeli Workers } \\
\hline & Name & Original & Year & Position at the time of pre- & \multicolumn{3}{|c|}{ Language } & \multirow{2}{*}{$\begin{array}{c}\text { Education } \\
\begin{array}{c}\text { ibtidai } \\
\text { private }\end{array}\end{array}$} \\
\hline 19 & $\begin{array}{l}\text { Mehmed } \\
\text { Arif Efendi } \\
\text { (Eğin) }\end{array}$ & 412 & 1860 & $\begin{array}{c}\text { İstanbul Kadılığı Sermuhzır- } \\
\text { lığı }\end{array}$ & $\begin{array}{l}\text { SR } \\
\text { W }\end{array}$ & & & \\
\hline 20 & $\begin{array}{l}\text { Abdi Efendi } \\
\text { (İstanbul) }\end{array}$ & 670 & 1845 & Mahkeme-i Evkaf muhzırlığı & RW & & & mahalle mektebi \\
\hline 21 & $\begin{array}{l}\text { Raşid Ağa } \\
\text { (Bitlis) }\end{array}$ & 630 & 1850 & $\begin{array}{l}\text { Galata Mahkemesi } \\
\text { hademeliği }\end{array}$ & & $S$ & $\Delta \mathrm{RW}$ & ibtidai \\
\hline 22 & $\begin{array}{l}\text { Hüsni Ağa } \\
\text { (Kemah) }\end{array}$ & 360 & 1883 & Meclis-i Meşayih odacıı̆ğı & $\mathrm{R}$ & & & $\begin{array}{l}\text { primary educa- } \\
\text { tion }^{*}\end{array}$ \\
\hline 23 & $\begin{array}{l}\text { Ahmed Ağa } \\
\text { (Malatya) }\end{array}$ & 400 & 1882 & $\begin{array}{l}\text { Memurin Müdiriyeti hade- } \\
\text { meliği }\end{array}$ & $\mathrm{R}$ & & $\Delta W$ & ibtidai \\
\hline 24 & $\begin{array}{l}\text { Mehmed } \\
\text { Ağa, 'Küzcük' } \\
\text { (Malatya) }\end{array}$ & 322 & 1859 & Daire-i Meşihat Kapı Ağalığı & $S$ & S & & $\begin{array}{c}\text { ibtidai } \\
\text { private (Ist.) }\end{array}$ \\
\hline 25 & $\begin{array}{l}\text { Şaban Ağa } \\
\text { (İşkodra) }\end{array}$ & 343 & 1869 & $\begin{array}{c}\text { Daire-i Meşihat bağçevan-ı } \\
\text { saniliği }\end{array}$ & $S$ & & & sibyan \\
\hline
\end{tabular}

Note: T=Turkish, K=Kurdish, Unsp.=Unspecified, $S=$ Speaking, R=Reading, $\mathrm{W}=$ Writing, $\boldsymbol{\Delta}=$ Inability, Asterisk $\left({ }^{*}\right)=$ With certain reservations, Ist. = Istanbul. Approximate year of birth in the Gregorian calendar is calculated by adding 584 to the year in the Ottoman fiscal calendar. Raşid (\#21) and Şaban (\#25) also spoke Armenian and Albanian, respectively. 